\section{Smith ScholarWorks}

10-1-2019

\section{Positive Genetic Associations Among Fitness Traits Support Evolvability of a Reef-Building Coral Under Multiple Stressors}

\author{
Rachel M. Wright \\ Smith College, rwright@smith.edu \\ Hanaka Mera \\ Australian Institute of Marine Science \\ Carly D. Kenkel \\ Australian Institute of Marine Science \\ Maria Nayfa \\ James Cook University \\ Line K. Bay \\ Australian Institute of Marine Science
}

See next page for additional authors

Follow this and additional works at: https://scholarworks.smith.edu/bio_facpubs

Part of the Biology Commons

\section{Recommended Citation}

Wright, Rachel M.; Mera, Hanaka; Kenkel, Carly D.; Nayfa, Maria; Bay, Line K.; and Matz, Mikhail V., "Positive Genetic Associations Among Fitness Traits Support Evolvability of a Reef-Building Coral Under Multiple Stressors" (2019). Biological Sciences: Faculty Publications, Smith College, Northampton, MA. https://scholarworks.smith.edu/bio_facpubs/178

This Article has been accepted for inclusion in Biological Sciences: Faculty Publications by an authorized administrator of Smith ScholarWorks. For more information, please contact scholarworks@smith.edu 


\section{Authors}

Rachel M. Wright, Hanaka Mera, Carly D. Kenkel, Maria Nayfa, Line K. Bay, and Mikhail V. Matz 


\title{
Positive genetic associations among fitness traits support evolvability of a reef-building coral under multiple stressors
}

\author{
Rachel M. Wright ${ }^{1,2,3}$ (D) | Hanaka Mera ${ }^{4}$ | Carly D. Kenkel ${ }^{4,5}$ (D) | Maria Nayfa ${ }^{6}$ | \\ Line K. Bay ${ }^{4}$ | Mikhail V. Matz ${ }^{3}$
}

${ }^{1}$ Department of Biological Sciences, Smith College, Northampton, MA, USA

${ }^{2}$ Department of Genetics, Harvard Medical School, Boston, MA, USA

${ }^{3}$ Department of Integrative Biology, The University of Texas at Austin, Austin, TX, USA

${ }^{4}$ Australian Institute of Marine Science, Townsville, QId, Australia

${ }^{5}$ Department of Biological

Sciences, University of Southern California, Los Angeles, CA, USA

${ }^{6}$ Centre for Sustainable Tropical Fisheries and Aquaculture, College of Science and Engineering, James Cook University,

Townsville, QId, Australia

Correspondence

Rachel M. Wright, Department of Biological Sciences, Smith College, 44 College Lane,

Northampton, MA 01063, USA.

Email: rwright@smith.edu

Funding information

National Science Foundation, Grant/Award Number: DBI-1401165; AIMS

\begin{abstract}
Climate change threatens organisms in a variety of interactive ways that requires simultaneous adaptation of multiple traits. Predicting evolutionary responses requires an understanding of the potential for interactions among stressors and the genetic variance and covariance among fitness-related traits that may reinforce or constrain an adaptive response. Here we investigate the capacity of Acropora millepora, a reef-building coral, to adapt to multiple environmental stressors: rising sea surface temperature, ocean acidification, and increased prevalence of infectious diseases. We measured growth rates (weight gain), coral color (a proxy for Symbiodiniaceae density), and survival, in addition to nine physiological indicators of coral and algal health in 40 coral genets exposed to each of these three stressors singly and combined. Individual stressors resulted in predicted responses (e.g., corals developed lesions after bacterial challenge and bleached under thermal stress). However, corals did not suffer substantially more when all three stressors were combined. Nor were trade-offs observed between tolerances to different stressors; instead, individuals performing well under one stressor also tended to perform well under every other stressor. An analysis of genetic correlations between traits revealed positive covariances, suggesting that selection to multiple stressors will reinforce rather than constrain the simultaneous evolution of traits related to holobiont health (e.g., weight gain and algal density). These findings support the potential for rapid coral adaptation under climate change and emphasize the importance of accounting for corals' adaptive capacity when predicting the future of coral reefs.
\end{abstract}

KEYWORDS

Acropora millepora, adaptation, covariance, multiple stressors, reef-building coral

\section{1 | INTRODUCTION}

Reef-building corals are experiencing unprecedented declines due to changing environmental conditions, such as rising sea surface temperatures that lead to coral bleaching, and ocean acidification

Line K. Bay and Mikhail V. Matz contributed equally. that impairs calcification (Andersson \& Gledhill, 2012; HoeghGuldberg et al., 2007). Climate change has also indirectly led to increasingly prevalent coral diseases, which are often attributed to the increased abundance and virulence of bacterial pathogens (BenHaim, 2003; Maynard et al., 2015; Pruzzo et al., 2010). In the face of these stressors, corals are left with few options but to move, adapt, or die. A number of studies have documented corals' capacities to 
expand their ranges to more suitable habitats (Makino et al., 2014; Yamano, Sugihara, \& Nomura, 2011). Models that simulate future coral cover under different climactic scenarios increasingly include estimates of adaptive capacity, such as simulated directional genetic selection (Logan, Dunne, Eakin, \& Donner, 2014) or predictions of the spread and persistence of alleles conferring thermal tolerance (Bay, Rose, Logan, \& Palumbi, 2017; Matz, Treml, Aglyamova, \& Bay, 2018). These studies primarily focus on a single environmental challenge (thermal stress) and do not predict interactive effects among simultaneous stressors or account for genetic associations between multiple tolerance traits.

Adaptation to rapidly changing conditions requires standing phenotypic variation upon which selection can act, provided that this heterogeneity has a genetic basis (i.e., that it is heritable). Although a large and ever-growing number of studies examine mean responses of coral species to individual effects of climate change (Marubini, Ferrier-Pages, \& Cuif, 2003; Okazaki et al., 2017), few have measured standing genetic variation and heritability of these responses (Dixon et al., 2015; Kenkel, Setta, \& Matz, 2015; van Oppen, Császár, Berkelmans, Ralph, \& Frankham, 2010; Vollmer \& Kline, 2008; Wang et al., 2009) and even fewer have assessed variation in multiple stress tolerance phenotypes (Shaw, Carpenter, Lantz, \& Edmunds, 2016). Corals exhibit remarkable variation in stress tolerance traits upon which selection could theoretically act (Baums et al., 2013; Dixon et al., 2015; Wright et al., 2017). However, univariate analyses assessing a single stress-response phenotype, such as mortality under bacterial challenge or bleaching under thermal stress, fail to fully describe the genetic basis of the phenotypes under selection. Selection is an inherently multivariate process that acts simultaneously on sets of functionally related traits. Indeed, centuries of animal and plant breeding have demonstrated that selection on one trait will often result in changes in another correlated trait (Rauw, Kanis, NoordhuizenStassen, \& Grommers, 1998; Zhao, Atlin, Bastiaans, \& Spiertz, 2006). Commercial demand for multiple-stress-tolerant crops has driven extensive research on stressor combinations in plants (Pandey, Irulappan, Bagavathiannan, \& Senthil-Kumar, 2017). In these plants, combinations of abiotic stressors and pathogens result in either resistance or susceptibility to disease, depending on the intensity or duration of stress (Pandey, Ramegowda, \& Senthil-Kumar, 2015). Positive associations between different stressors can be attributed to shared pathways. For example, some biotic and abiotic stressors stimulate the same defense-related endogenous signals (Mithöfer, Schulze, \& Boland, 2004). Alternatively, stress responses may compete for demands on energetic reserves, resulting in a negative association in tolerances, or a trade-off (Sokolova, 2013).

The prospects for future reef-building corals are exceedingly pessimistic without rapid adaptation to a number of simultaneous stressors. This capacity for adaptation is determined by the answer to an outstanding question: does success under one type of stress come at a cost of susceptibility to a co-occurring environmental challenge? To address this critical knowledge gap, we quantified the capacity for Acropora millepora, a model representative of a keystone group of marine organisms that are among the most vulnerable to climate change (Reusch, 2014), to adapt to simultaneous stressors. Multiple coral colonies ( $n=40$, hereafter referred to as "genets") were split into replicate clonal fragments ( $n=5$ per treatment) that were exposed to elevated temperature $\left(30^{\circ} \mathrm{C}\right)$, increased $\mathrm{pCO}_{2}$ $\left(\mathrm{pH}=7.8,700 \mathrm{ppm} \mathrm{CO}_{2}\right)$, bacterial challenge $\left(10^{6} \mathrm{CFU} / \mathrm{ml}\right.$ Vibrio owensii), a combination of these three stressors at the same levels, or a control condition $\left(27^{\circ} \mathrm{C}, \mathrm{pH}=8.0,400 \mathrm{ppm} \mathrm{CO}_{2}\right.$, no added $\mathrm{V}$. owensii). We measured a comprehensive suite of coral host and algal traits to assess each genet's performance in each condition and constructed a genetic variance-covariance matrix to identify potential genetic trade-offs or reinforcements between phenotypes.

\section{MATERIALS AND METHODS}

\section{1 | Study organism and aquarium conditions}

Colonies of A. millepora were sampled between October and December 2014 from Davies Reef lagoon (78 km offshore; $18^{\circ} 50^{\prime} 11^{\prime \prime} \mathrm{S}$, $147^{\circ} 38^{\prime} 41^{\prime \prime} \mathrm{E}$ ), Rib Reef (56 km offshore; $18^{\circ} 28^{\prime} 55^{\prime \prime} \mathrm{S}, 146^{\circ} 52^{\prime} 15^{\prime \prime} \mathrm{E}$ ), Pandora Reef ( $16 \mathrm{~km}$ offshore; $18^{\circ} 48^{\prime} 44^{\prime \prime} \mathrm{S}, 146^{\circ} 25^{\prime} 59^{\prime \prime} \mathrm{E}$ ), and Esk Island (24 km offshore; $18^{\circ} 46^{\prime} 04^{\prime \prime} \mathrm{S}, 146^{\circ} 30^{\prime} 57^{\prime \prime} \mathrm{E}$ ). These colonies were transferred to holding tanks at the National Sea Simulator system at the Australian Institute of Marine Science (Townsville, Queensland, Australia). After approximately 2 weeks of acclimatization, each colony was fragmented into 25 replicate fragments ("nubbins"), which were mounted on aragonite plugs and placed on replicate trays. Trays were maintained in six indoor holding tanks which were supplied with $0.2 \mu \mathrm{M}$ filtered seawater (FSW) at $27^{\circ} \mathrm{C}$. Three lights (AI Aqua Illumination) were suspended above each tank providing an average underwater light intensity of $180 \mu \mathrm{mol}$ photons $\mathrm{m}^{-2} \mathrm{~s}^{-1}$ on a 10-/14-hr light-dark cycle. Corals were fed freshly hatched Artemia nauplii twice daily and cleaned three times a week to prevent algal growth. Coral nubbins were acclimated to these conditions for 3-5 months, depending on the date of collection. Unique genets were later confirmed via 2b-RAD genotyping (Wang, Meyer, Mckay, \& Matz, 2012). The final total genets for each sampling location are as follows: Davies ( $n=10)$, Rib $(n=10)$, Pandora $(n=14)$, and Esk $(n=6)$. Algal symbiont types were investigated by ITS- 2 sequencing for eight of the coral colonies (Howe-Kerr et al., 2019).

\section{2 | Experimental treatments and sample preparation}

On March 2, 2015, coral nubbins (25 per genet) were placed into twenty-five $50 \mathrm{~L}$ treatment tanks fitted with $3.5-\mathrm{W}$ Turbelle nanostream 6015 pumps (Tunze) with flow-through seawater at $\sim 25 \mathrm{~L} / \mathrm{hr}$ at the same temperature and light conditions as in the previous holding tanks. Initial weights for each nubbin were obtained following the method described by Davies (1989). All nubbins were approximately the same size (mean $=7.62 \mathrm{~g}, S D=1.08 \mathrm{~g}$ ). Tanks ( $n=5$ per treatment) were allocated to the following treatments: elevated temperature $\left(30^{\circ} \mathrm{C}\right)$, increased $\mathrm{pCO}_{2}(700 \mathrm{ppm}$, $\mathrm{pH}=7.8)$, bacterial challenge $\left(10^{6} \mathrm{CFU} / \mathrm{ml} \mathrm{V}\right.$. owensii DY05), a 
combined treatment $\left(30^{\circ} \mathrm{C}, 700 \mathrm{ppm}, 10^{6} \mathrm{CFU} / \mathrm{ml} \mathrm{V}\right.$. owensii), and control $\left(27^{\circ} \mathrm{C}, 400 \mathrm{ppm}, \mathrm{pH}=8.0\right.$, no bacteria). This isolate of non-quarantined $\mathrm{V}$. owensii had been recently sampled during an infectious disease outbreak in cultured lobsters at the research facility. Temperature and $p \mathrm{CO}_{2}$ were gradually increased in their respective tanks over the course of a week to $30^{\circ} \mathrm{C}$ and $400 \mathrm{ppm}$ $(\mathrm{pH}=8.0)$. The bacterial challenge was conducted in separate isolated tanks (no flow through) and consisted of a daily 6-hr incubation. Vibrio owensii was added at a final concentration of $10^{6} \mathrm{CFU} / \mathrm{ml}$ to every bacterial challenge tank, including the combined treatment (which was also maintained at $30^{\circ} \mathrm{C}$ and $700 \mathrm{ppm}$ $p \mathrm{CO}_{2}$ for these $6 \mathrm{hr}$ ). Corals were then returned to their respective treatment tanks until the next day's bacterial challenge and the bacterial challenge tanks were treated with $20 \%$ bleach for at least $30 \mathrm{~min}$. Coral fragments were photographed daily to quantify bleaching via the Coral Health Chart (Siebeck, Marshall, Klüter, \& Hoegh-Guldberg, 2006) and lesion progression. Net oxygen production and the changes in total alkalinity under light were measured for randomly selected genets adapting methods described in Strahl et al. (2015). Briefly, coral nubbins were incubated in enclosed acrylic chambers at respective treatment temperatures for $1.5 \mathrm{hr}$, alongside blanks to subtract the background metabolic activity. The $\mathrm{O}_{2}$ concentration of the seawater in each chamber was measured after the incubation period using a dissolved oxygen meter (HQ30d, equipped with LDO101 IntelliCAL oxygen probe, Hach). A subsample of seawater (120 ml) in each chamber was fixed with $0.5 \mathrm{mg}$ mercuric chloride and the total alkalinity was measured using a Titrando 855 Robotic Titrosampler (Metrohm AG). Fragments exhibiting any tissue loss or that were fully bleached and exhibiting algal growth were removed from treatment tanks, buoyant weighed, and preserved in liquid nitrogen. The time of death (day post initial exposure) was recorded at each instance. We stopped the experiment after 10 consecutive days of treatment. At this time, many fragments presented severe tissue loss, which meant they could not be used in downstream physiological assays (Figure S1). To preserve enough clonal replication to make statistical comparisons across genets, we ended the experiment when symptoms were apparent but total mortality was relatively low (approximately $21 \%$ ). Eleven days after the initial challenge, all surviving corals were photographed, buoyant weighed, preserved in liquid nitrogen, and stored at $-80^{\circ} \mathrm{C}$ until sample processing.

Tissue was removed from coral skeletons using an air gun and $0.2 \mu \mathrm{M}$ filtered seawater and homogenized for $60 \mathrm{~s}$ using a Pro250 homogenizer (Perth Scientific Equipment). A $1 \mathrm{ml}$ aliquot of the tissue homogenate was centrifuged for $3 \mathrm{~min}$ at $1,500 \mathrm{~g}$ at $4^{\circ} \mathrm{C}$ and the pellet was stored at $-80^{\circ} \mathrm{C}$ for chlorophyll analyses. The remaining homogenate was centrifuged for $3 \mathrm{~min}$ at $1,500 \mathrm{~g}$ at $4^{\circ} \mathrm{C}$ to separate host and symbiont fractions. The fractions were frozen in 96-well tissue culture plates and stored at $-80^{\circ} \mathrm{C}$. Coral skeletons were rinsed with $10 \%$ bleach and then dried at room temperature $\left(\sim 24^{\circ} \mathrm{C}\right)$. Skeletal surface area was quantified using the single paraffin wax dipping method (Stimson \& Kinzie, 1991) and skeletal volume was determined by calculating water displacement in a graduated cylinder.

\section{3 | Physiological trait assays}

Assays were conducted to detect cellular and metabolic activity changes within Symbiodiniaceae or coral host tissue in response to the treatment. All standards and samples were loaded as duplicates, and absorbance was recorded with a Cytation 3 multi-mode microplate reader (BioTek) and analyzed using Gen5 software (BioTek).

To quantify chlorophyll concentrations, tissue homogenate algal pellets were resuspended in $1 \mathrm{ml}$ chilled $90 \%$ acetone. The homogenate was sonicated on ice for $10 \mathrm{~s}$ at $40 \%$ amplitude, left in the dark for $20 \mathrm{~min}$, and centrifuged for $5 \mathrm{~min}$ at $10,000 \mathrm{~g}$ at $4^{\circ} \mathrm{C}$. A $200 \mu \mathrm{l}$ aliquot of sample extract was loaded to a 96-well plate, and absorbance was recorded at 630 and $663 \mathrm{~nm}$. Chlorophyll $a$ and $c 2$ concentrations were calculated with the equations in Jeffrey and Haxo (1968) and were normalized to surface area:

$$
\begin{aligned}
& \text { Chlorophyll } a(\mu \mathrm{g} / \mathrm{ml})=13.31 \times A_{663}-0.27 \times A_{630} \\
& \text { Chlorophyll } c 2(\mu \mathrm{g} / \mathrm{ml})=51.72 \times A_{630}-8.37 \times A_{663} .
\end{aligned}
$$

A commercial colorimetric protein assay kit (DCTM Protein Assay Kit, Bio-Rad) was used to quantify total protein content of the coral host tissue. A $100 \mu \mathrm{l}$ aliquot of Symbiodiniaceae-free coral tissue sample was digested using $100 \mu$ l sodium hydroxide in a 96-well plate for $1 \mathrm{hr}$ at $90^{\circ} \mathrm{C}$. The plate was centrifuged for $3 \mathrm{~min}$ at $1,500 \mathrm{~g}$. Following the manufacturer's instructions, $5 \mu \mathrm{l}$ digested tissue was mixed with $25 \mu$ l alkaline copper tartrate solution and $200 \mu$ l dilute Folin reagent in a fresh 96 -well plate. The absorbance at $750 \mathrm{~nm}$ was recorded after a 15-min incubation. Sample protein concentrations were calculated using a standard curve of bovine serum albumin ranging from 0 to $1,000 \mu \mathrm{g} / \mathrm{ml}$.

Carbohydrate content of the Symbiodiniaceae-free coral tissue was estimated following the method of Masuko et al. (2005) that measures monosaccharides, including glucose, which is the major photosynthate translocated between symbionts and host corals (Burriesci, Raab, \& Pringle, 2012). A $50 \mu \mathrm{l}$ aliquot of coral tissue was mixed with $150 \mu \mathrm{l}$ concentrated sulfuric acid and $30 \mu \mathrm{l} 5 \%$ phenol in a 96-well plate for $5 \mathrm{~min}$ at $90^{\circ} \mathrm{C}$. After another 5 -min incubation at room temperature, the absorbance at $485 \mathrm{~nm}$ was recorded. The total carbohydrate concentrations of samples were calculated using a standard curve of D-glucose solutions ranging from 0 to $2,000 \mu \mathrm{g} / \mathrm{ml}$.

To analyze nonfluorescent chromoprotein content, a $30 \mu \mathrm{l}$ aliquot of coral tissue was loaded to a black/clear 384-well plate and the absorbance was recorded at $588 \mathrm{~nm}$. Mean absorbance was standardized to sample protein content.

The activity of catalase (CA), a reactive oxygen species scavenging enzyme (Lesser, 2006), was measured by estimating the change in hydrogen peroxide $\left(\mathrm{H}_{2} \mathrm{O}_{2}\right)$ substrate concentration. A $20 \mu$ laliquot of coral tissue was mixed with $30 \mu \mathrm{l} 50 \mathrm{mM}$ phosphate-buffered saline solution ( $\mathrm{pH} 7.0$ ) and $50 \mu \mathrm{l} 50 \mathrm{mM} \mathrm{H}_{2} \mathrm{O}_{2}$ in a 96-well plate. CA 
was calculated as the change in absorbance at $240 \mathrm{~nm}$ every $30 \mathrm{~s}$ over the linear portion of the reaction curve for $15 \mathrm{~min}$ and was standardized to sample protein content:

$$
\mathrm{CA}(\mathrm{mg} / \text { protein })=\text { Initial } A_{240}-\text { Final } A_{240} .
$$

The change in coral color was estimated using photographs taken during the experiment with a Nikon D300 digital camera. Brightness values were measured over the entire front and back sections of each nubbin using image analysis software (ImageJ, NIH). Corals become brighter (whiter) when they lose darkly colored algal symbionts, so changes in brightness reflect changes in Symbiodiniaceae densities (Beer, Loya, Winters, Holzman, \& Blekhman, 2009). A standard curve of brightness values was constructed using standard coral color cards that were present in each image. Brightness values were standardized to color cards to normalize for differences across photo sessions.

\section{4 | Statistical analyses}

The time of death was noted for each individual nubbin. Survival was modeled as time of death $\sim$ treat + reef $+(1 \mid$ tank) using coxme package in R 3.3.1 (R Core Team, 2016; Therneau, 2019), where treatment was specified as the presence or absence of elevated heat, bacteria, or increased $p \mathrm{CO}_{2}$ (e.g., bacteria = 1 for "V. owensii" and "combined" treatments; heat $=1$ for " $30^{\circ} \mathrm{C}$ " and combined" treatments). All subsequent analyses were performed on lesion-free (alive) corals. Data were log-transformed using powers determined by Box-Cox transformations performed using the powerTransform function in the $\mathrm{R}$ package car (Fox \& Weisberg, 2011). Linear mixed-effects models implemented using the R package nlme (Pinheiro, Bates, DebRoy, $\&$ Sarkar, 2018) tested the effects of treatments and reef-of-origin on trait values. As described above, four levels of treatment were specified as the presence or absence of each stressor. For example, the combined and bacterial challenge conditions are coded as "present" for the bacterial challenge stressor, whereas the elevated $p \mathrm{CO}_{2}$ and $30^{\circ} \mathrm{C}$ conditions are "absent" for the bacterial treatment. The stepAIC function in the R package MASS (Venables \& Ripley, 2002) determined which terms to include in the best-fit model. Principal components analysis on mean-centered and variance-scaled values was performed using the prcomp function in base R. Pearson correlations between trait values were calculated using the cor function in base $\mathrm{R}$, and correlation heatmaps were constructed using the corrplot function. The genetic variance-covariance matrix was constructed using the R package MCMCgImm (Hadfield, 2010). Trait data were mean-centered and variance scaled. The multivariate model was fit for four traits (growth, color, chlorophyll c2, and carbohydrate) with treatment as a fixed effect and genet as a random effect, using the idh variance structure. The model was run for 20,000 iterations after a 5,000 iteration burn-in, storing the Markov chain after 20 iteration intervals. Partial regression coefficients for each trait on binomial survival outcome were modeled using a categorical MCMCgImm model with genet as a random effect. The selection gradient was composed of these partial regression coefficients, scaled to unit variance. Predicted changes in trait values $(\Delta \bar{z})$ were calculated using the multivariate breeder's equation (Lande \& Arnold, 1983):

$$
\Delta \overline{\mathbf{z}}=\mathbf{G} \beta,
$$

where $\mathbf{G}$ is the genetic variance-covariance matrix and $\beta$ is the selection gradient.

\section{3 | RESULTS}

\section{1 | Mean responses to treatments}

\subsection{1 | Survival}

Corals in the control condition experienced the lowest mortality at $13.5 \%$, followed by increased temperature (21.5\%), combined treatment (23.7\%), bacteria challenge (26.4\%), and elevated $\mathrm{pCO}_{2}$ (27.4\%). Treatment was specified as the presence or absence of each stressor. The Cox proportional hazards model included each treatment and reef as fixed effects, with tank as a random effect. Bacteria challenge significantly increased mortality rates (hazard ratio $[\mathrm{HR}]=3.32, p=.018)$. In the last days of the experiment, corals in the elevated $p \mathrm{CO}_{2}$ treatment experienced high mortality, but mortality rates in corals under this condition were indistinguishable from control corals throughout the first week of the experiment (Figure 1a). We did not detect a significant difference in mortality between the control and elevated $p \mathrm{CO}_{2}$ treatment, as the Cox proportional hazards model compares mortality across the entire period. Colonies from Rib reef had the lowest mortality (16.5\%). Colonies from Davies and Esk reefs had higher mortality rates ( $\mathrm{HR}=0.54, p=.007$ and $\mathrm{HR}=0.58, p=.01$, respectively) than those from Rib (Figure S2).

\section{2 | Physiological responses}

We measured the following algal and host-associated traits from surviving coral fragments: coral color (an indicator of Symbiodiniaceae densities), algal chlorophyll $a$ and chlorophyll $c 2$ content, total host carbohydrate, total host protein, host CA activity, host chromoprotein content, oxygen production (indicator of photosynthetic rate), instant calcification rate, and change in buoyant weight (skeletal growth).

Chromoprotein content and CA (Figure 1b,c) serve as proxies for coral innate immune response. We found no significant effect of treatment on either of these measurements. Bleaching was calculated as a log-transformed change in color in photographs standardized to the Coral Health Chart (Siebeck et al., 2006). Bacteria treatment made corals significantly darker $(\beta=.70, p<.001)$, whereas corals became lighter (i.e., bleached) in the elevated temperature treatment $(\beta=-.54$, $p<.001$; Figure 1e). The elevated temperature treatment resulted in worse bleaching than the combined treatment $(\beta=-.86, p<.001)$. These findings are corroborated by chlorophyll measurements: bacterial treatment increased chlorophyll $a(\beta=2.1, p<.001$; Figure 1f) and c2 ( $\beta=1.0, p=.001$; Figure $1 \mathrm{~g})$ content in the algal fraction of the coral 


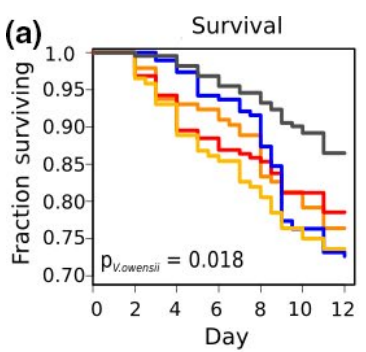

(e)
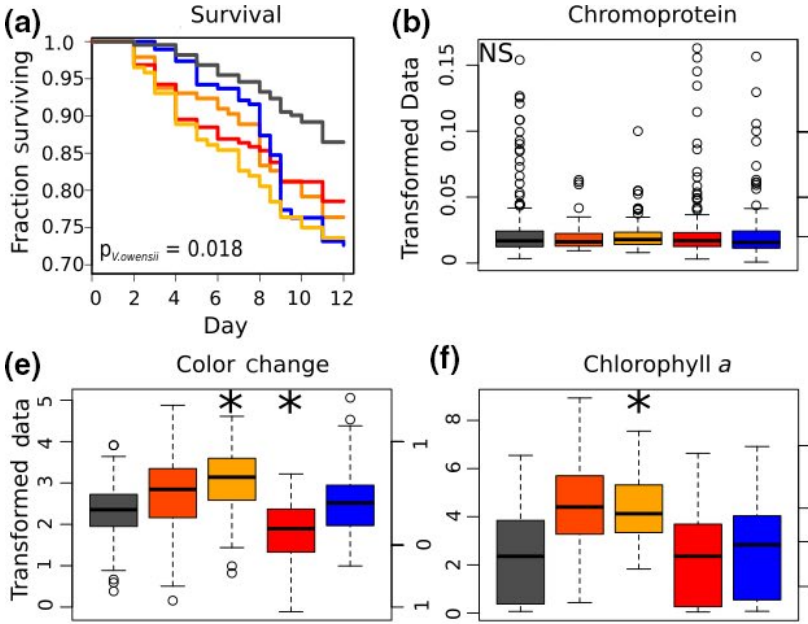

(f)

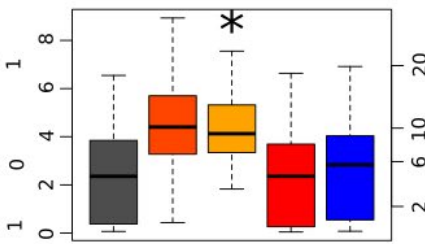

(i) $\mathrm{O}_{2}$ production

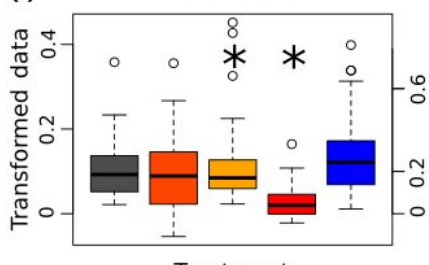

Treatment

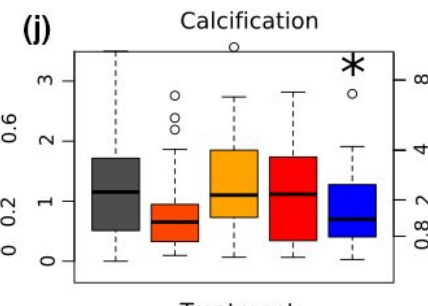

(c)
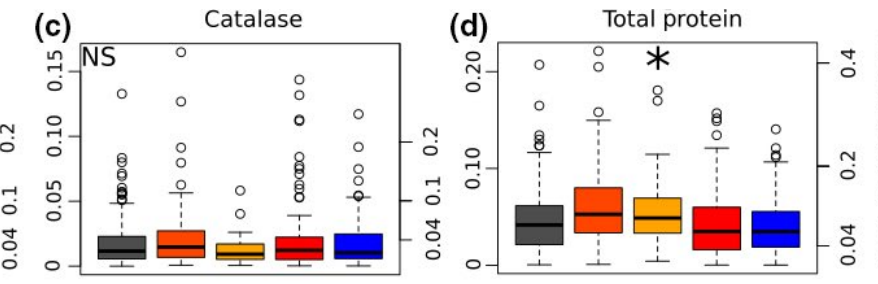

(g)

Chlorophyll c2

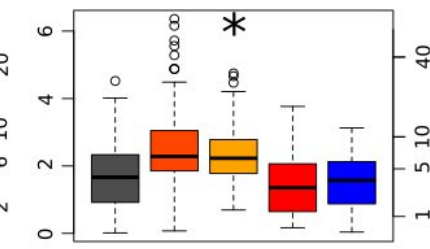

(h)

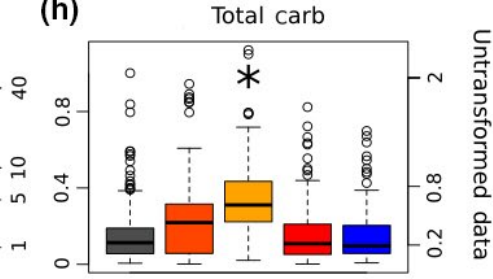

Treatment

\begin{abstract}
(k)
\end{abstract}

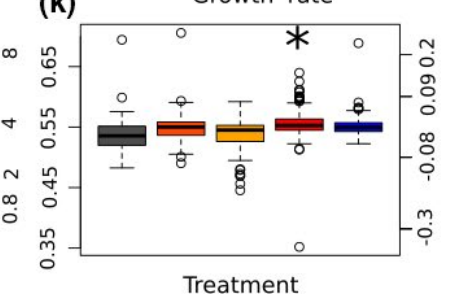

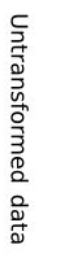

FIGURE 1 Mean responses to treatment. (a) Survival fraction over the duration of the experiment. Colors correspond to treatment (see inset key). (b-k) Box-Cox power transformed trait values separated (left axis) and untransformed trait values (right axis) by treatment (indicated by color in legend). The bottom and top of each box represent the lower and upper quartiles, respectively. Whiskers span $1.5 \times$ the interquartile range. NS = no significant effect of treatment. Asterisks indicate a significant $(p<.05)$ effect of the indicated treatment relative to the control condition. (b) Chromoprotein content $\left(A_{588} \cdot \mu \mathrm{g} /\right.$ protein). (c) Catalase activity $\left(\Delta \mathrm{H}_{2} \mathrm{O}_{2} \cdot \mathrm{mg} \operatorname{protein}^{-1} \mathrm{~min}^{-1}\right)$. (d) Total protein content $\left(\mathrm{mg} / \mathrm{cm}^{2}\right)$. (e) Coral fragment color change (final - initial score). Chlorophyll $a(\mathrm{f})$ and $\mathrm{c} 2(\mathrm{~g})$ content $\left(\mu \mathrm{g} / \mathrm{cm}^{2}\right)$. (h) Total carbohydrate $\left(\mathrm{mg} / \mathrm{cm}^{2}\right)$. (i) Oxygen production $\left(\mathrm{mg} \mathrm{O}_{2} \mathrm{~cm}^{-2} \mathrm{~min}^{-1}\right)$. (j) Instant calcification rate ( $\left.\mu \mathrm{mol} \mathrm{CaCO} \mathrm{cm}^{-2} \mathrm{~min}^{-1}\right)$. (k) Buoyant weight growth rate (\% $\Delta$ weight $\mathrm{g} /$ day)

tissue. Bacterial treatment increased the carbohydrate content in the coral host tissues ( $\beta=.73, p<.001$; Figure $1 \mathrm{~h}$ ).

Photosynthetic and instant calcification rates were measured for a smaller subset of the coral genets. As expected, the elevated temperatures reduced photosynthetic rates ( $\beta=-.51, p<.001$; Figure 1i). The bacterial treatment improved algal traits under bacterial challenge (Figure $1 \mathrm{e}-\mathrm{g}$ ). Only the elevated $p \mathrm{CO}_{2}$ treatment affected instant calcification rates, decreasing them on average $(\beta=-.48, p=.01$; Figure $1 \mathrm{j}$ ). Buoyant weights of each fragment were measured at the beginning of the experiment and when each fragment was removed from the experiment. Corals in the elevated temperature treatment experienced moderately increased growth rates $(\beta=.017, p=.04$; Figure $1 \mathrm{k}$ ). Buoyant weights were not significantly affected by any other treatment.

\section{3 | Phenotypic space, correlations, and evolvability calculations}

The lack of synergistic treatment effects on coral fitness proxies provides encouraging evidence for an individual coral's capacity to resist multiple stressors. To investigate whether a population of corals can adapt to multiple threats, we looked for potential trade-offs by measuring correlations between stressor effects across genets.

Principal components analysis explored patterns in phenotypic space of 429 individual fragments (Figure 2a) with complete datasets for growth, color change, chlorophyll $a$, chlorophyll c2, chromoprotein, $\mathrm{CA}$, and survival fraction (the proportion of fragments surviving for the genet in each respective treatment). The first principal component explained $30.2 \%$ of the variation and separates samples by differential algal responses to treatment (Figure 2a,b). The second principal component explained $16.2 \%$ of the variation and separates samples by host immune enzyme responses (chromoprotein and CA activity).

We calculated Pearson correlations by genet across treatments for five traits with the most complete data and clearest link to fitness: survival fraction, growth rate, color change, chlorophyll c2 content, and total host carbohydrate (Figure 3). The correlation heatmaps show many positive and statistically significant correlations between trait pairs and very few negative correlations, none of which were statistically significant (Figure 3). Survival fractions for each genet are significantly positively correlated among treatments (Figure 3a). In other words, individuals that show high fitness characteristics under one stressor also perform well under other stressors. 


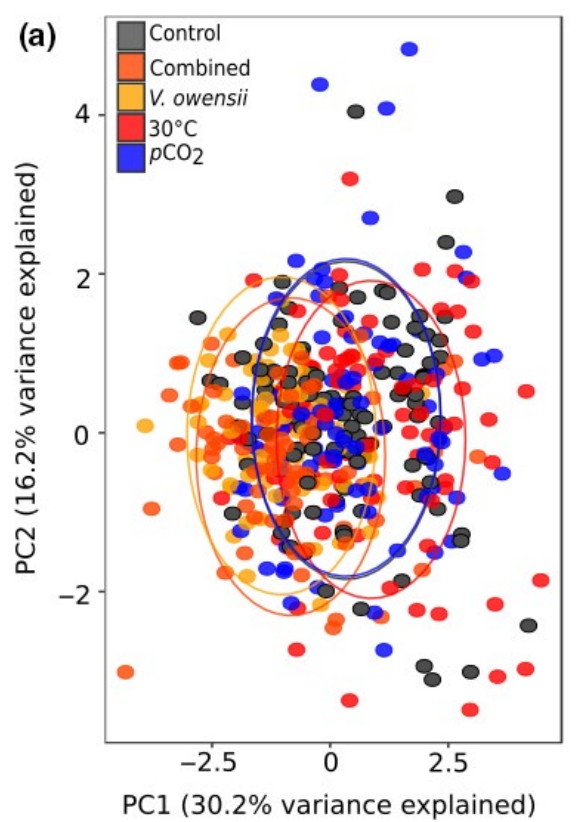

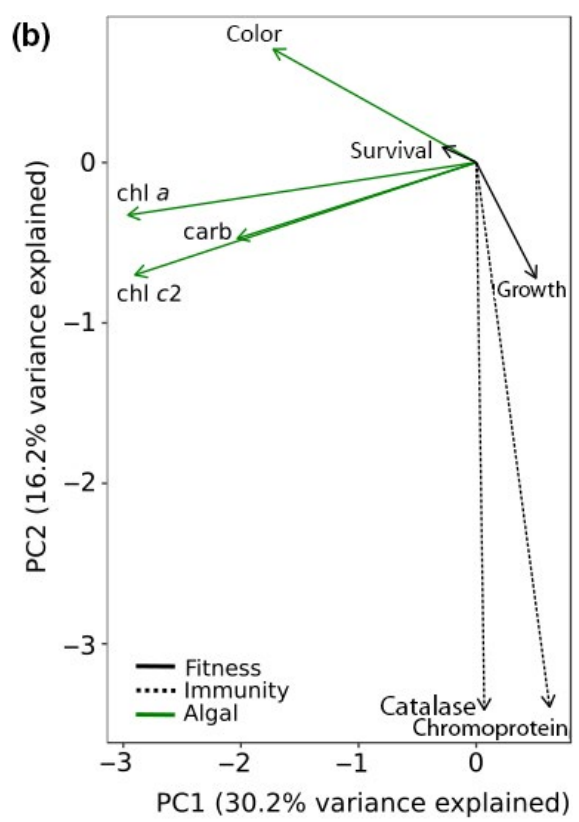

FIGURE 2 Principal components analysis. (a) Principal components analysis based on physiological trait data for 429 fragments. (b) Loadings for traits along the first two principal components axes. Data point colors represent the treatment in which the coral fragment was placed. Colors and line shapes of loadings identify traits related to algal parameters (green), immune enzyme activity (dashed), or general coral fitness (black) (a) Survival fraction

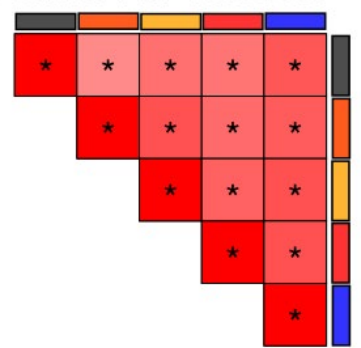

(b) Growth rate

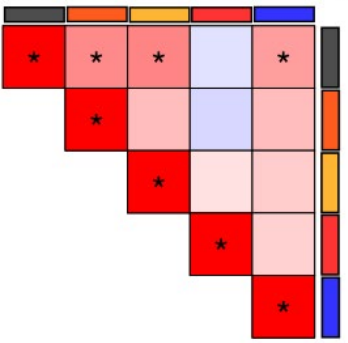

(c) Color change

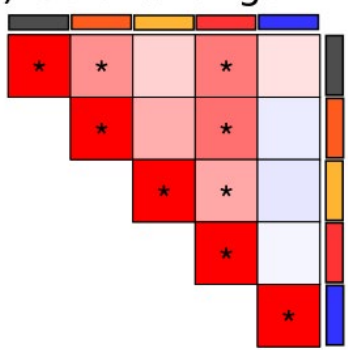

(d) Chlorophyll c2

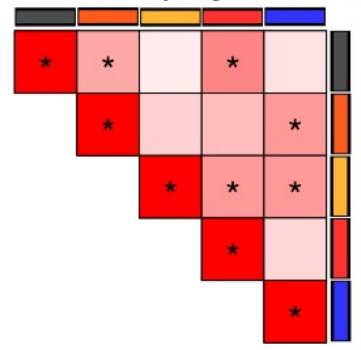

(e) Carbohydrate

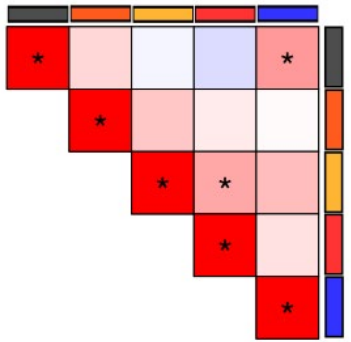

FIGURE 3 Pearson correlation heatmaps based on scaled average (a) survival fraction, (b) growth rate, (c) color change, (d) chlorophyll c2 content, and (e) carbohydrate content for 39 genets. Colored bars indicate the treatment measurement. Colors within the heatmap squares represent the magnitude and direction of the Pearson correlation according to the key. Significant $(p<.05)$ correlations are indicated with asterisks
Pairwise comparisons do not adequately capture the overall genetic covariance of traits in the population. To further explore the evolvability of these traits, we constructed a genetic variancecovariance matrix ( $G$ matrix) by selecting four traits that describe various aspects of host and symbiont fitness: color change, weight gain, chlorophyll c2 content, and carbohydrate content. All genetic correlations between these traits were positive (Figure 4a).

In multivariate trait space, the response of a trait to selection may deviate from the direction of selection due to influences of genetically associated traits. Depending on the shape of genetic variance-covariance matrix (G matrix) and selection strength on individual traits, fitness traits may or may not be able to evolve in concert. To investigate this issue in our coral, we calculated a selection gradient (a vector of partial regression coefficients standardized to unit length) by regressing the four traits against binomial survival ( 1 = fragment survived; 0 = fragment died). All selection coefficients were positive (Figure 4a), although only growth was significantly associated with survival $(p<.001)$. We then applied the multivariate breeder's equation to estimate how trait values would change given our $\mathbf{G}$ matrix and selection for higher survival under moderate stressors (Figure 4b). Since all selection coefficients and covariances were positive, the change in every trait over one generation was also positive (Figure $4 \mathrm{~b}$ ). This result implies that fitness traits should be able to co-evolve together and moreover, reinforce each other's evolution, that is, corals with high survival rates would also tend to produce offspring with increased growth rates, carbohydrate content, 

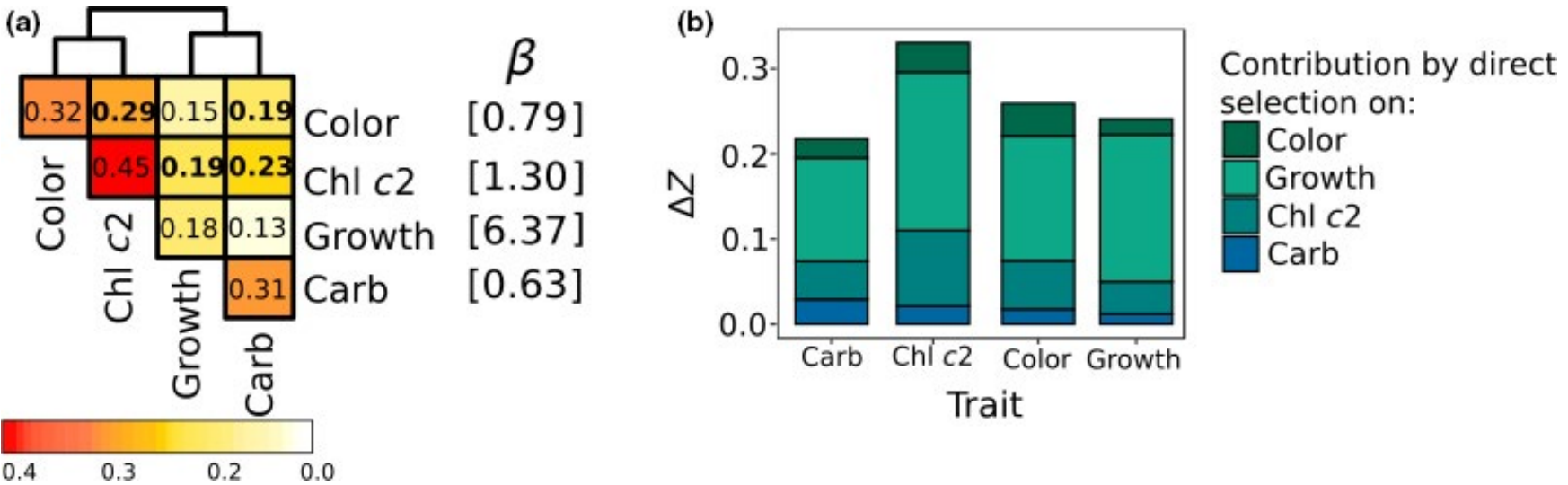

FIGURE 4 (a) Left: Genetic variance-covariance matrix for four fitness traits across five treatments in 39 genets. The color in the inset key and number within each box quantifies trait variances (diagonal elements) and covariances between paired traits (off-diagonal elements). Bold font denotes significant associations. Right: Selection gradient $(\beta)$, a vector of partial regression coefficients for each trait on survival. (b) Changes in trait means $(\Delta Z)$ per unit of selection for higher survival under multiple stressors. Each stacked bar is composed of the direct effect of selection on the trait and effects of selection on each of the genetically correlated traits

Symbiodiniaceae densities, and chlorophyll content under different stressors.

To demonstrate this reinforcement effect, we decomposed the total predicted change in each trait (the total height of each bar in Figure $4 \mathrm{~b}$ ) into the contribution of selection directly on that trait or on the three covarying traits. For example, a predicted increase in chlorophyll $c 2$ content is mostly driven by selection on growth rate, which is more strongly correlated with survival and is genetically correlated with chlorophyll c2 content (Figure 4a). The model predicts less improvement in color (a proxy of algal symbiont density) and host carbohydrate content because these traits covary less with growth rate and are not themselves strongly associated with survival (Figure 4a).

\section{4 | DISCUSSION}

\subsection{Mean effects of single and combined stressors}

At the end of our 10-day challenge, each experimental treatment largely resulted in the expected mean response. Elevated temperatures reduced algal parameters (Symbiodiniaceae densities, chlorophyll $a$ and $c 2$ content), analogous to a natural coral bleaching event. Bacteria challenge resulted in the development of lesions and caused an unexpected increase in algal traits. Although a meta-analysis of coral stress responses predicted that the detrimental effects of most stressors are enhanced by the presence of another stressor (Ban, Graham, \& Connolly, 2014) and other empirical studies have documented compromised coral immunity and increased prevalence of coral disease concurrent with thermal stress (Bruno et al., 2007; Palmer, 2018), we did not observe detrimental interactive effects of the combined challenge. A tempting hypothesis to explain this phenomenon is that elevated temperature exposure prior to pathogen exposure primed the coral's stress response system to mitigate oxidative stress associated with launching an innate immune response (Lu, Wang, \& Liu, 2015).
We also saw that coral bleaching was minimized in the combined treatment relative to thermal stress alone (Figure 1e), possibly as a result of heterotrophic feeding (Bourne, Morrow, \& Webster, 2016): both coral host and algal symbiont had access to extra nutrients (bacterial inoculations triply washed in sterile seawater) in the combined treatment. Further supporting this hypothesis is the unexpected observation of increased algal traits in the bacteria-only treatment. Reef-building corals feed on bacteria (Houlbrèque \& Ferrier-Pagès, 2009), which could act as a beneficial nutrient source to encourage algal productivity (Rädecker, Pogoreutz, Voolstra, Wiedenmann, \& Wild, 2015; Sawall, Al-Sofyani, Banguera-Hinestroza, \& Voolstra, 2014). Heterotrophic compensation has been investigated as a method by which corals withstand extended bleaching events (Baumann, Grottoli, Hughes, \& Matsui, 2014; Grottoli, Rodrigues, \& Palardy, 2006; Hughes \& Grottoli, 2013), but the capacity for heterotrophic feeding to prevent bleaching deserves more attention.

\section{2 | Best performing genets tolerate multiple stressors}

Pairwise correlations of trait values in each treatment revealed mostly positive associations across all genets. Importantly, survival rates were significantly positively correlated under most treatments (Figure 3; Figure S3), indicating the absence of trade-offs with respect to an individual's ability to withstand different disturbances. Individuals that could survive one stressful condition tended to be able to manage other stressors as well. There were a few exceptions involving Symbiodiniaceae: color under bacterial challenge was negatively correlated with survival under bacterial challenge or under thermal stress, and also negatively correlated with growth under control conditions and under bacterial challenge. Again, Symbiodiniaceae density measurements in corals exposed to Vibrio in this experiment may reflect the ability of a coral to improve algal traits due to the presence of bacteria as a result of increased heterotrophic feeding. 
Given the drastically different phenotypic responses to each stressor applied in this study (e.g., symbiont expulsion vs. tissue loss), it is reasonable to expect to observe trade-offs in a coral's ability to manage each challenge. Presumably these unique stressors require the coral to employ distinct molecular response mechanisms, which come at a metabolic cost. This study cannot offer a mechanism to explain the positive associations in stress tolerances observed in these corals, but the literature offers promising areas for further investigation. In corals, the oxidative theory for bleaching under thermal stress posits that reactive oxygen species (ROS) accumulation damages cells and triggers symbiont expulsion (Lesser, 1997). ROS are also produced in response to immune challenges to exert antimicrobial activity and stimulate immune signaling pathways (Bogdan, Röllinghoff, \& Diefenbach, 2000). Innate immune activiation limits pathogen growth and poses immunopathological risk to the host; thus, a maximal immune response is not always optimal (Viney, Riley, \& Buchanan, 2005) and antioxidant mitigation of self-harm is necessary for survival (Knight, 2000). Elevated $p \mathrm{CO}_{2}$ has also been shown to trigger oxidative stress in corals (Davies, Marchetti, Ries, \& Castillo, 2016) and oysters (Tomanek, Zuzow, Ivanina, Beniash, \& Sokolova, 2011). Given the critical role of managing oxidative stress in responses to thermal stress, elevated $p \mathrm{CO}_{2}$, and bacterial challenge, the robustness of a coral's antioxidant defense system to prevent self-harm may underlie tolerance to all three of these stressors. A recent study in rice identified an allele of the transcription factor Ideal Plant Architecture 1 that simultaneously confers improved growth and immune function by toggling between phosphorylation states that drive expression in distinct subsets of gene targets (Wang et al., 2018). Future studies should critically evaluate the nature of shared pathways in coral stress responses.

Another consideration is the contribution of the algal symbiont toward holobiont health. In this study, colonies primarily hosted Cladocopium symbionts almost exclusively, but also contained lower abundances of Brevolium, Durusdinium, and/or Gerakladinium symbionts ( $<0.1 \%$ of the total community; Howe-Kerr et al., 2019). Notably, one colony contained a larger proportion of Durusdinium and was among the worst performing colonies in this experiment. Though we do not observe a clear contribution of any one symbiont type on overall host health in this study, as other studies have demonstrated (Rouzé, Lecellier, Saulnier, \& Berteaux-Lecellier, 2016; Silverstein, Cunning, \& Baker, 2017), future studies should continue to investigate how algal symbionts modify coral responses to environmental stressors.

Furthermore, the extent to which algal traits can be used to predict host adaptation in a broadcast spawning, horizontally transmitting coral species is worthy of discussion and further investigation. Previous studies in another horizontal transmitter, Orbicella faveolata, have shown that the genetic identity of the coral host explains more than $70 \%$ of the variation in proportions of Symbiodiniaceae genera hosted, and by implication, in bleaching responses (Manzello et al., 2019). In an acroporid species, heritability of symbiont community was high: host genetics accounted for about $29 \%$ of the variation in symbiont profiles between adult parents and their juvenile offspring (Quigley, Willis, \& Bay, 2017). One could expect an even higher similarity in symbiont profiles across generations with additional winnowing through development. Larval and axenic adult Aiptasia ingest algae indiscriminately but employ host cell-specific mechanisms to selectively phagocytose compatible symbiont strains to establish stable symbiosis (Hambleton et al., 2018). Post-phagocytotic host mechanisms allow further symbiont strain selection in Montipora capitata (Dunn \& Weis, 2009). In general, symbiosis and dysbiosis (bleaching) is always a result of interaction between host and symbiont, and while it might be not $100 \%$ heritable when viewed from the perspective of the coral host (because of symbiont contribution), there is every reason to expect it to be evolvable due to the substantial coral influence on what kinds of symbionts are hosted and how they are managed (e.g., Barfield, Aglyamova, Bay, \& Matz, 2018).

\section{3 | Positive genetic associations of fitness traits suggest holobiont adaptability}

Multivariate analyses describe how fitness traits may change under directional selection. The variance-covariance structure estimated in this study indicates that our focal species possesses the genetic heterogeneity and flexibility to respond to multiple selective pressures. The positive genetic covariances between four traits associated with holobiont fitness (growth, Symbiodiniaceae density, chlorophyll c2 content, and total carbohydrate content) argue for reinforced evolution of all traits (Figure 4). In our study, growth rate is most strongly associated with survival under climate change stressors and therefore would be predicted to evolve rapidly due to direct selection pressure. Another study identified a positive association between growth and survival in situ, though this association was weak and did not persist across multiple years of observation (Edmunds, 2017). In our experiment, although directional selection is weaker for other traits (algal density, carbohydrate content, and chlorophyll c2 content), genetic correlation with growth rate would result in their increases as well. However, it is important to note that our experiment cannot disentangle genetic associations that are due to host, symbiont, or their specific combination. Our conclusions regarding the effect of selection on fitness traits would hold only if genetic interactions between host and symbiont do not contribute much to fitness trait variation (i.e., if most of the trait variance is attributable to a simple sum of variances due to host and symbiont). More research on study systems where holobiont genetic composition can be manipulated (e.g., coral recruits) is necessary to resolve this issue.

Furthermore, our findings are limited to the experimental conditions included in this study. While infectious disease, heat-induced bleaching, and ocean acidification are major contributors to reef devastation, other disturbances also have widespread effects on coral health. This study cannot account for other coral threats, such as physical damage and photic habitat changes caused by hurricanes (Edmunds, Tsounis, Boulon, \& Bramanti, 2019) and mortality by predation (Kayal et al., 2012). We observe no trade-off in a coral's ability to manage the stressors at the duration and level applied in this 
experiment, but we cannot rule out potential limitations in a coral's ability to respond to every possible threat and disturbance regime. Additionally, though secondary responses (e.g., heat-induced bacterial microbiome shifts that may lead to chronic disease; Pootakham et al., 2018) are certainly important to the long-term fate of reef-building corals, this experiment aimed to quantify the immediate, primary host responses to individual stressors. Given our relatively brief treatment, we can be reasonably sure that we observed only rapid induction primary responses to the experimental perturbation. Given more time in each treatment, corals may have developed secondary responses, such as heat-stress induced necrotic disease (Jones, Bowyer, \& HoeghGuldberg, 2004), that would confound our interpretation of individual stress responses. Lastly, our 10-day experimental challenge captured the immediate responses to these different stressors. Future studies should address whether the patterns of covariance in stress tolerances persist after longer exposures to each treatment, though our results suggest that the weakest genets would be completely dead, rendering many other traits uninformative, within about 2 weeks.

\section{4 | Considerations for future reefs}

The management implications of these findings are twofold. Firstly, adaptive processes should not be ignored in ecological climate modeling. Dire estimates for future coral cover are often derived from experiments in which a coral from today is placed under conditions predicted decades into the future (Okazaki et al., 2017). Acropora millepora can reach reproductive maturity as early as 3 years after fertilization (Baria, dela Cruz, Villanueva, \& Guest, 2012) and thus, modeling strategies based on end-of-the-century climate scenarios ignore dozens of generations of potential adaptive evolution. Our results suggest that this adaptation can proceed because coral fitness traits tend to reinforce, rather than constrain, adaptation toward improved fitness under multiple environmental challenges. Secondly, our results should be taken into account during efforts to spread adaptive genetic variation by propagating, translocating, and breeding genets that have survived a natural stress event, although latent effects of the stress event may impact thermal tolerance into the future. Regardless of the method used to select broodstock for coral reseeding, our results strongly suggest that colonies should be selected for restoration in a manner that does not jeopardize corals' natural ability to adapt, for example through a narrowing of the gene pool. In the absence of severe bottlenecks in genetic diversity, natural selection will continue selecting for corals that thrive despite multiple harassments brought about by climate change. However, this adaptation will only proceed if reproduction is maintained under increasingly hostile conditions and until adaptive genetic variation starts running out (Matz et al., 2018), and therefore our findings should not undermine the critical urgency to limit anthropogenic climate change.

\section{ACKNOWLEDGEMENTS}

We would like to thank the staff of AIMS research vessel the RV Cape Ferguson and the National Sea Simulator for assistance with coral colony collection and experiments. This work was supported by funding provided by AIMS to L.B.K. and C.D.K., and NSF DBI-1401165 to C.D.K. The collections were supported by a permit from the Great Barrier Reef Marine Park Authority permit numbers G11/34671.1 and G14/37318.1.

\section{ORCID}

Rachel M. Wright (iD https://orcid.org/0000-0002-5867-1224

Carly D. Kenkel iD https://orcid.org/0000-0003-1126-4311

\section{REFERENCES}

Andersson, A. J., \& Gledhill, D. (2012). Ocean acidification and coral reefs: Effects on breakdown, dissolution, and net ecosystem calcification. Annual Review of Marine Science, 5(1), 321-348. https://doi. org/10.1146/annurev-marine-121211-172241

Ban, S. S., Graham, N. A. J., \& Connolly, S. R. (2014). Evidence for multiple stressor interactions and effects on coral reefs. Global Change Biology, 20(3), 681-697. https://doi.org/10.1111/gcb.12453

Barfield, S. J., Aglyamova, G. V., Bay, L. K., \& Matz, M. V. (2018). Contrasting effects of Symbiodinium identity on coral host transcriptional profiles across latitudes. Molecular Ecology, 27(15), 3103-3115. https://doi.org/10.1111/mec.14774

Baria, M. V. B., dela Cruz, D. W., Villanueva, R. D., \& Guest, J. (2012). Spawning of three-year-old Acropora millepora corals reared from larvae in northwestern Philippines. Bulletin of Marine Science, 88(1), 61-62. https://doi.org/10.5343/bms.2011.1075

Baumann, J., Grottoli, A. G., Hughes, A. D., \& Matsui, Y. (2014). Photoautotrophic and heterotrophic carbon in bleached and non-bleached coral lipid acquisition and storage. Journal of Experimental Marine Biology and Ecology, 461, 469-478. https://doi.org/10.1016/j.jembe.2014.09.017

Baums, I. B., Devlin-Durante, M. K., Polato, N. R., Xu, D., Giri, S., Altman, N. S., ... Boulay, J. N. (2013). Genotypic variation influences reproductive success and thermal stress tolerance in the reef building coral, Acropora palmata. Coral Reefs, 32(3), 703-717. https://doi. org/10.1007/s00338-013-1012-6

Bay, R. A., Rose, N. H., Logan, C. A., \& Palumbi, S. R. (2017). Genomic models predict successful coral adaptation if future ocean warming rates are reduced. Science Advances, 3(11), 1-10. https://doi. org/10.1126/sciadv.1701413

Beer, S., Loya, Y., Winters, G., Holzman, R., \& Blekhman, A. (2009). Photographic assessment of coral chlorophyll contents: Implications for ecophysiological studies and coral monitoring. Journal of Experimental Marine Biology and Ecology, 380(1-2), 25-35. https:// doi.org/10.1016/j.jembe.2009.09.004

Ben-Haim, Y. (2003). Vibrio coralliilyticus sp. nov., a temperature-dependent pathogen of the coral Pocillopora damicornis. International Journal of Systematic and Evolutionary Microbiology, 53(1), 309-315. https://doi.org/10.1099/ijs.0.02402-0

Bogdan, C., Röllinghoff, M., \& Diefenbach, A. (2000). The role of nitric oxide in innate immunity. Immunological Reviews, 173(1), 17-26. https ://doi.org/10.1034/j.1600-065X.2000.917307.x

Bourne, D. G., Morrow, K. M., \& Webster, N. S. (2016). Insights into the coral microbiome: Underpinning the health and resilience of reef ecosystems. Annual Review of Microbiology, 70(1), 317-340. https:// doi.org/10.1146/annurev-micro-102215-095440

Bruno, J. F., Selig, E. R., Casey, K. S., Page, C. A., Willis, B. L., Harvell, C. D., ... Melendy, A. M. (2007). Thermal stress and coral cover as drivers of coral disease outbreaks. PLoS Biology, 5(6), e124. https://doi. org/10.1371/journal.pbio.0050124 
Burriesci, M. S., Raab, T. K., \& Pringle, J. R. (2012). Evidence that glucose is the major transferred metabolite in dinoflagellate-cnidarian symbiosis. The Journal of Experimental Biology, 215(Pt 19), 3467-3477. https:// doi.org/10.1242/jeb.070946

Davies, P. S. (1989). Short-term growth measurements of corals using an accurate buoyant weighing technique. Marine Biology, 101(3), 389395. https://doi.org/10.1007/BF00428135

Davies, S. W., Marchetti, A., Ries, J. B., \& Castillo, K. D. (2016). Thermal and $\mathrm{pCO}_{2}$ stress elicit divergent transcriptomic responses in a resilient coral. Frontiers in Marine Science, 3, https://doi.org/10.3389/ fmars.2016.00112

Dixon, G. B., Davies, S. W., Aglyamova, G. A., Meyer, E., Bay, L. K., \& Matz, M. V. (2015). Genomic determinants of coral heat tolerance across latitudes. Science, 348, 1460-1462. https://doi.org/10.1126/ science.1261224

Dunn, S. R., \& Weis, V. M. (2009). Apoptosis as a post-phagocytic winnowing mechanism in a coral-dinoflagellate mutualism. Environmental Microbiology, 11(1), 268-276. https://doi. org/10.1111/j.1462-2920.2008.01774.x

Edmunds, P. (2017). Intraspecific variation in growth rate is a poor predictor of fitness for reef corals. Ecology, 98(8), 2191-2200. https:// doi.org/10.1002/ecy.1912

Edmunds, P., Tsounis, G., Boulon, R., \& Bramanti, L. (2019). Acute effects of back-to-back hurricanes on the underwater light regime of a coral reef. Marine Biology, 166, https://doi.org/10.1007/ s00227-018-3459-z

Fox, J., \& Weisberg, S. (2011). An R companion to applied regression (2nd ed.). Thousand Oaks, CA: Sage. Retrieved from http://socserv.socsci. mcmaster.ca/jfox/Books/Companion.

Grottoli, A. G., Rodrigues, L. J., \& Palardy, J. E. (2006). Heterotrophic plasticity and resilience in bleached corals. Nature, 440(7088), 11861189. https://doi.org/10.1038/nature04565

Hadfield, J. D. (2010). MCMC methods for multi-response generalized linear mixed models: The MCMCgImm R package. Journal of Statistical Software, 33(2), 1-22. https://doi.org/10.1002/ana.22635

Hambleton, E., Jones, V. A. S., Maegele, I., Kvaskoff, D., Sachsenheimer, T., \& Guse, A. (2018). Enhanced stability of non-canonical NPC2 in the symbiosome supports coral-algal symbiosis. BioRxiv, 399766 , https://doi.org/10.1101/399766

Hoegh-Guldberg, O., Mumby, P. J., Hooten, A. J., Steneck, R. S., Greenfield, P., Gomez, E., ... Hatziolos, M. E. (2007). Coral reefs under rapid climate change and ocean acidification. Science, 318, 1737-1742. https://doi.org/10.1126/science.1152509

Houlbrèque, F., \& Ferrier-Pagès, C. (2009). Heterotrophy in tropical scleractinian corals. Biological Reviews, 84(1), 1-17. https://doi. org/10.1111/j.1469-185X.2008.00058.x

Howe-Kerr, L., Bachelot, B., Wright, R. M., Kenkel, C. D., Bay, L. K., \& Correa, A. M. S. (2019). Symbiont community diversity is more constrained in holobionts that tolerate diverse stressors. BioRxiv. https://doi.org/10.1101/572479

Hughes, A. D., \& Grottoli, A. G. (2013). Heterotrophic compensation: A possible mechanism for resilience of coral reefs to global warming or a sign of prolonged stress? PLOS ONE, 8(11), 1-10. https://doi. org/10.1371/journal.pone.0081172

Jeffrey, S., \& Haxo, H. (1968). Photosynthetic pigments of symbiotic dinoflagellates (zooxanthellae) from corals and clams. Biological Bulletin, 135, 149-165. https://doi.org/10.2307/1539622

Jones, R. J., Bowyer, J., \& Hoegh-Guldberg, O. (2004). Dynamics of a temperature-related coral disease outbreak. Marine Ecology Progress Series, 281, 63-77. https://doi.org/10.3354/meps281063

Kayal, M., Vercelloni, J., Lison de Loma, T., Bosserelle, P., Chancerelle, Y., Geoffroy, S., ... Adjeroud, M. (2012). Predator crown-of-thorns starfish (Acanthaster planci) outbreak, mass mortality of corals, and cascading effects on reef fish and benthic communities. PLoS ONE, 7(10), https://doi.org/10.1371/journal.pone.0047363
Kenkel, C. D., Setta, S. P., \& Matz, M. V. (2015). Heritable differences in fitness-related traits among populations of the mustard hill coral, Porites astreoides. Heredity, 115(6), 509-516. https://doi. org/10.1038/hdy.2015.52

Knight, J. A. (2000). Review: Free radicals, antioxidants, and the immune system. Annals of Clinical and Laboratory Science, 30(2), 145-158.

Lande, R., \& Arnold, S. (1983). The measurement of selection on correlated characters. Evolution, 37, https://doi.org/10.2307/2408842

Lesser, M. (1997). Oxidative stress causes coral bleaching during exposure to elevated temperatures. Coral Reefs, 16(3), 187-192. https:// doi.org/10.1007/s003380050073

Lesser, M. (2006). Oxidative stress in marine environments: Biochemistry and physiological ecology. Annual Review of Physiology, 68, 253-278. https://doi.org/10.1146/annurev.physiol.68.040104.110001

Logan, C. A., Dunne, J. P., Eakin, C. M., \& Donner, S. D. (2014). Incorporating adaptive responses into future projections of coral bleaching. Global Change Biology, 20(1), 125-139. https://doi.org/10.1111/gcb.12390

Lu, X., Wang, C., \& Liu, B. (2015). The role of Cu/Zn-SOD and Mn-SOD in the immune response to oxidative stress and pathogen challenge in the clam Meretrix. Fish and Shellfish Immunology, 42(1), 58-65. https:// doi.org/10.1016/j.fsi.2014.10.027

Makino, A., Yamano, H., Beger, M., Klein, C. J., Yara, Y., \& Possingham, H. P. (2014). Spatio-temporal marine conservation planning to support high-latitude coral range expansion under climate change. Diversity and Distributions, 20(8), 859-871. https://doi.org/10.1111/ddi.12184

Manzello, D. P., Matz, M. V., Enochs, I. C., Valentino, L., Carlton, R. D., Kolodziej, G., ... Jankulak, M. (2019). Role of host genetics and heattolerant algal symbionts in sustaining populations of the endangered coral Orbicella faveolata in the Florida Keys with ocean warming. Global Change Biology, 25, 1016-1031. https://doi.org/10.1111/ gcb. 14545

Marubini, F., Ferrier-Pages, C., \& Cuif, J. P. (2003). Suppression of skeletal growth in scleractinian corals by decreasing ambient carbonate-ion concentration: A cross-family comparison. Proceedings of the Royal Society B: Biological Sciences, 270(1511), 179-184. https://doi. org/10.1098/rspb.2002.2212

Masuko, T., Minami, A., Iwasaki, N., Majima, T., Nishimura, S., \& Lee, Y. (2005). Carbohydrate analysis by a phenol-sulfuric acid method in a microplate format. Analytical Biochemistry, 339(1), 69-72. https://doi. org/10.1016/j.ab.2004.12.001

Matz, M. V., Treml, E. A., Aglyamova, G. V., \& Bay, L. K. (2018). Potential and limits for rapid genetic adaptation to warming in a Great Barrier Reef coral. PLoS Genetics, 14(4), 1-19. https://doi.org/10.1371/journ al.pgen. 1007220

Maynard, J., van Hooidonk, R., Eakin, C. M., Puotinen, M., Garren, M., Williams, G., ... Harvell, C. D. (2015). Projections of climate conditions that increase coral disease susceptibility and pathogen abundance and virulence. Nature Climate Change, 5(7), 688-694. https:// doi.org/10.1038/nclimate2625

Mithöfer, A., Schulze, B., \& Boland, W. (2004). Biotic and heavy metal stress response in plants: Evidence for common signals. FEBS Letters, 566(1-3), 1-5. https://doi.org/10.1016/j.febslet.2004.04.011

Okazaki, R. R., Towle, E. K., van Hooidonk, R., Mor, C., Winter, R. N., Piggot, A. M., ... Langdon, C. (2017). Species-specific responses to climate change and community composition determine future calcification rates of Florida Keys reefs. Global Change Biology, 23(3), 1023-1035. https://doi.org/10.1111/gcb.13481

Palmer, C. V. (2018). Warmer water affects immunity of a tolerant reef coral. Frontiers in Marine Science, 5(July), 1-9. https://doi. $\operatorname{org} / 10.3389 /$ fmars.2018.00253

Pandey, P., Irulappan, V., Bagavathiannan, M. V., \& Senthil-Kumar, M. (2017). Impact of combined abiotic and biotic stresses on plant growth and avenues for crop improvement by exploiting physio-morphological traits. Frontiers in Plant Science, 8(April), 1-15. https://doi. org/10.3389/fpls.2017.00537 
Pandey, P., Ramegowda, V., \& Senthil-Kumar, M. (2015). Shared and unique responses of plants to multiple individual stresses and stress combinations: Physiological and molecular mechanisms. Frontiers in Plant Science, 6(September), 1-14. https://doi.org/10.3389/fpls.2015.00723

Pinheiro, J., Bates, D., DebRoy, S., Sarkar, D., \& R Core Team. (2018). nlme: Linear and nonlinear mixed effects models. R Package Version 3.1-137. Retrieved from https://CRAN.R-project.org/package=nlme.

Pootakham, W., Mhuantong, W., Putchim, L., Yoocha, T., Sonthirod, C., Kongkachana, W., ... Tangphatsornruang, S. (2018). Dynamics of coral-associated microbiomes during a thermal bleaching event. MicrobiologyOpen, 7(5), e00604. https://doi.org/10.1002/mbo3.604

Pruzzo, C., Cerrano, C., Marchese, A., Bourne, D. G., Previati, M., \& Vezzulli, L. (2010). Vibrio infections triggering mass mortality events in a warming Mediterranean Sea. Environmental Microbiology, 12(7), 2007-2019. https://doi.org/10.1111/j.1462-2920.2010.02209.x

Quigley, K. M., Willis, B. L., \& Bay, L. K. (2017). Heritability of the Symbiodinium community in vertically- and horizontally-transmitting broadcast spawning corals. Scientific Reports, 7(1), 8219. https://doi. org/10.1038/s41598-017-08179-4

R Core Team. (2016). R: A language and environment for statistical computing. Vienna, Austria: R Foundation for Statistical Computing.

Rädecker, N., Pogoreutz, C., Voolstra, C. R., Wiedenmann, J., \& Wild, C. (2015). Nitrogen cycling in corals: The key to understanding holobiont functioning? Trends in Microbiology, 23(8), 490-497. https://doi. org/10.1016/j.tim.2015.03.008

Rauw, W. M., Kanis, E., Noordhuizen-Stassen, E. N., \& Grommers, F. J. (1998). Undesirable side effects of selection for high production efficiency in farm animals: A review. Livestock Production Science, 56(1), 15-33. https://doi.org/10.1016/S0301-6226(98)00147-X

Reusch, T. B. H. (2014). Climate change in the oceans: Evolutionary versus phenotypically plastic responses of marine animals and plants. Evolutionary Applications, 7(1), 104-122. https://doi.org/10.1111/ eva.12109

Rouzé, H., Lecellier, G., Saulnier, D., \& Berteaux-Lecellier, V. (2016). Symbiodinium clades A and D differentially predispose Acropora cytherea to disease and Vibrio spp. colonization. Ecology and Evolution, 6(2), 560-572. https://doi.org/10.1002/ece3.1895

Sawall, Y., Al-Sofyani, A., Banguera-Hinestroza, E., \& Voolstra, C. R. (2014). Spatio-temporal analyses of Symbiodinium physiology of the coral Pocillopora verrucosa along large-scale nutrient and temperature gradients in the Red Sea. PLoS ONE, 9(8), 1-12. https://doi. org/10.1371/journal.pone.0103179

Shaw, E. C., Carpenter, R. C., Lantz, C. A., \& Edmunds, P. J. (2016). Intraspecific variability in the response to ocean warming and acidification in the scleractinian coral Acropora pulchra. Marine Biology, 163(10), https://doi.org/10.1007/s00227-016-2986-8

Siebeck, U. E., Marshall, N. J., Klüter, A., \& Hoegh-Guldberg, O. (2006). Monitoring coral bleaching using a colour reference card. Coral Reefs, 25(3), 453-460. https://doi.org/10.1007/s00338-006-0123-8

Silverstein, R. N., Cunning, R., \& Baker, A. C. (2017). Tenacious D: Symbiodinium in clade $D$ remain in reef corals at both high and low temperature extremes despite impairment. The Journal of Experimental Biology, 220(7), 1192-1196. https://doi.org/10.1242/jeb.148239

Sokolova, I. M. (2013). Energy-limited tolerance to stress as a conceptual framework to integrate the effects of multiple stressors. Integrative and Comparative Biology, 53(4), 597-608. https://doi.org/10.1093/icb/ict028

Stimson, J., \& Kinzie, R. A. (1991). The temporal pattern and rate of release of zooxanthellae from the reef coral Poscillopora damicornis (Linnaeus) under nitrogen-enrichment and control conditions. Journal of Experimental Marine Biology and Ecology, 153, 63-74. https ://doi.org/10.1016/s0022-0981(05)80006-1

Strahl, J., Stolz, I., Uthicke, S., Vogel, N., Noonan, S. H. C., \& Fabricius, K. E. (2015). Physiological and ecological performance differs in four coral taxa at a volcanic carbon dioxide seep.
Comparative Biochemistry and Physiology - Part A: Molecular and Integrative Physiology, 184, 179-186. https://doi.org/10.1016/j. cbpa.2015.02.018

Therneau, T. M. (2019). coxme: Mixed effects Cox models. R package version 2.2-14. Retrieved from https://CRAN.R-project.org/package= coxme.

Tomanek, L., Zuzow, M. J., Ivanina, A. V., Beniash, E., \& Sokolova, I. M. (2011). Proteomic response to elevated $\mathrm{PCO}_{2}$ level in eastern oysters, Crassostrea virginica: Evidence for oxidative stress. Journal of Experimental Biology, 214(11), 1836-1844. https://doi.org/10.1242/ jeb. 055475

van Oppen, M. J. H., Császár, N. B. M., Berkelmans, R., Ralph, P. J., \& Frankham, R. (2010). Estimating the potential for adaptation of corals to climate warming. PLoS ONE, 5(3), e9751. https://doi.org/10.1371/ journal.pone.0009751

Venables, W. N., \& Ripley, B. D. (2002). Modern applied statistics with S (4th ed.). New York, NY: Springer. ISBN 0-387-95457-0.

Viney, M. E., Riley, E. M., \& Buchanan, K. L. (2005). Optimal immune responses: Immunocompetence revisited. Trends in Ecology \& Evolution, 20(12), 665-669. https://doi.org/10.1016/j.tree.2005.10.003

Vollmer, S. V., \& Kline, D. I. (2008). Natural disease resistance in threatened staghorn corals. PLoS ONE, 3(11), 1-5. https://doi.org/10.1371/ journal.pone.0003718

Wang, J., Zhou, L., Shi, H., Chern, M., Yu, H., Yi, H., ... Chen, X. (2018). A single transcription factor promotes both yield and immunity in rice. Science, 361, 1026-1028. https://doi.org/10.1126/science.aat7675

Wang, S., Meyer, E., Mckay, J. K., \& Matz, M. V. (2012). 2b-RAD: A simple and flexible method for genome-wide genotyping. Nature Methods, 9(8), 808-810. https://doi.org/10.1038/nmeth.2023

Wang, S., Willis, B., Abrego, D., Davies, S., Juenger, T., Matz, M., \& Meyer, E. (2009). Genetic variation in responses to a settlement cue and elevated temperature in the reef-building coral Acropora millepora. Marine Ecology Progress Series, 392(Ipcc 2007), 81-92. https://doi. org/10.3354/meps08208

Wright, R. M., Kenkel, C. D., Dunn, C. E., Shilling, E. N., Bay, L. K., \& Matz, M. V. (2017). Intraspecific differences in molecular stress responses and coral pathobiome contribute to mortality under bacterial challenge in Acropora millepora. Scientific Reports, 7(1), 1-13. https://doi. org/10.1038/s41598-017-02685-1

Yamano, H., Sugihara, K., \& Nomura, K. (2011). Rapid poleward range expansion of tropical reef corals in response to rising sea surface temperatures. Geophysical Research Letters, 38(4), 11-20. https://doi. org/10.1029/2010GL046474

Zhao, D. L., Atlin, G. N., Bastiaans, L., \& Spiertz, J. H. J. (2006). Cultivar weed-competitiveness in aerobic rice: Heritability, correlated traits, and the potential for indirect selection in weed-free environments. Crop Science, 46(1), 372-380. https://doi.org/10.2135/crops ci2005.0192

\section{SUPPORTING INFORMATION}

Additional supporting information may be found online in the Supporting Information section at the end of the article.

How to cite this article: Wright RM, Mera H, Kenkel CD, Nayfa M, Bay LK, Matz MV. Positive genetic associations among fitness traits support evolvability of a reef-building coral under multiple stressors. Glob Change Biol. 2019;00: 1-11. https://doi.org/10.1111/gcb.14764 